\title{
Staying alive in academia: Collective praxis at work
}

\begin{abstract}
Internationally, as the twenty-first century unfolds, there is a burgeoning literature that documents the changing nature of academic work and work places. One recurring theme in this literature is the extent to which academic freedom and autonomy are being threatened in higher education settings. In this article, the nature of this ominous threat and what might be done about it are interrogated using praxis as a conceptual lens. On one meaning of praxis, we consider the actions of academics as individuals aiming for 'right conduct'; on a second meaning, we consider praxis as collective 'history-making action'. An analysis of the existing practices of researchers in two international settings revealed particular kinds of practice architectures - collective research practices - that have revitalised and sustained the working lives of these academics. The notion of collective praxis is suggested as a model of intellectual engagement for building communicative connections. It provides a strategic way forward both to enable academic freedom and autonomy and to benefit the institutions in which academics work.
\end{abstract}

Academic work is generally constituted by active involvement in the fields of research, teaching and administration although some academics are employed to strategically focus on only one or two of these fields. The major changes currently affecting academic work and workplaces have been succinctly identified in a review of current literature by Gappa, Austin and Trice (2007) as: fiscal constraints, escalating competition, demands for greater accountability from external sources, growing enrolments, increasingly diverse faculty appointments and the continuous expansion of new technologies. The findings from American universities seem to resonate strongly with other studies focused on the work and lifeworlds of academics in Europe, Australia and elsewhere (see, for example, Altbach 2001; Gould 2006; Jones, 2006; Karran 2007; Lafferty and Fleming 2000).

Given these current circumstances, change seems to have become the new constant in the everyday working lives of academics. In fact, life as an academic in the twenty-first century is constantly evolving. It seems that academics across the globe are experiencing various kinds of economic and political change that can simultaneously inspire, intrigue and irritate. These major changes can be viewed as traditions that are often external to the academics affected by them. Based on this body of work it would be easy to position academics as pawns in the accountability game, as operatives rather than agents in their own institutions. However, the intellectual capital of institutions predominantly resides in the academics that live and work in them. Gappa et al. (2007) warn that if higher education institutions ignore the importance of nurturing the intellectual vitality and agency of academics, they do so at their own peril.

\section{Being and Becoming an academic in academia}

In this article we take a deliberate stance of positioning academics as agents of change and managers of their own destinies. Our aim is to characterize the capacity of some academics, who work within the organisational structures of their institutions, to nurture and manage change through participating in collective research practices. Aspects of communities of practice (Wenger, 1998) and communicative space - as adapted from the work of Jurgen Habermas by Kemmis and McTaggart (2004) - have provided the 
thinking tools for conceptualizing, and understanding these practices and the ways in which they contribute to safeguarding a sense of freedom and autonomy in a climate of unpredictability.

An underlying assumption of the authors is that being an academic necessitates a continual process of becoming that is inherently social in nature. A related assumption is that the process of becoming is enhanced when academic practices are made accessible for critical reflection, discussion and reconstruction. Wenger's (1998) social theory of learning identifies markers of influence that support and enable scholars in academia seeking to open communicative spaces. Engagement in social practice plays a fundamental role in this theory where issues of identity are inseparable from issues of practice, community and meaning. Critical features of a community of practice are framed around three characteristics: mutual engagement, joint enterprise and a shared repertoire of practice. These features of a community parallel those required for 'opening communicative spaces' that strive for intersubjective agreement, mutual understanding, and unforced consensus (Kemmis \& McTaggart, 2004). Taken together, these features have the potential to inform and guide an analysis of the actions of academics who sought to remake the practices in which they lived and worked.

\section{Praxis and collective praxis development}

Kemmis and Smith (2008) remind us that praxis is always a process of becoming that involves careful consideration of the character, conduct and consequences of an act for self and others and the moral agency to act or not to act at a particular time and place. Praxis is always a social act and these actions (or non-actions) are historically located in life histories and traditions of practice that pre-figure our actions - what Kemmis and Grootenboer (2008) call 'practice architectures'. In Faculties of Education, for example, academic lives are nested within multiple practice architectures because the nature of the work crosses many structural boundaries. When a newly appointed academic arrives in an institution he or she will experience established traditions such as how university mission statements, student learning outcomes, and performance-based indicators are framed and the normative practices of 'how we do things around here' that accompany those frameworks. Similarly, academics inherit institutional policies and practices, organisational structures and gain access to available resources (human, fiscal and physical resources) that go with the job. Moreover, the allocation of, and access to, these resources can often reflect an established distribution of power that is politically motivated and deeply embedded in the culture and traditions of the institution. On any particular day a mix of varying activities take place: supervision of a student on practicum, work with pre-service teachers in an on-campus workshop, evaluation for purposes of performance-based management, completion of pressing administrative tasks required for accountability purposes or writing up an ongoing research project funded by a government grant. It is no wonder that Gappa et al. (2006) identified expanding workloads and the escalating pace of work in higher education settings as vital considerations in terms of institutional responsiveness and went on to implore 'strategic investment in the intellectual capital of the institution (p. 6). 
Developing the capacity to effectively work with, within, and around institutional structures seems paramount to developing personal praxis as an academic - the agency and academic freedom to do the best that one can do and to act in ways that are honest, morally defensible and self-actualising. However, when the demands of a work place do not align with an academic's personal praxis, his or her creativity and energy can be difficult to maintain. Collective praxis, as we describe it in the two cases below, addresses this issue by describing how groups of academics within and/or outside their own institutions created sites for the practice of communicative action by extending individual praxis into the realm of collective activity. What makes such activity a form of collective praxis is that its members sought the type of intellectual engagement that not only sustained personal praxis, but also enabled the collaborative transformation of particular practice architectures that seemed alienating, unproductive or unjust (Kemmis $\&$ McTaggart, 2004). This type of collective action often emanates from a felt dissatisfaction with an existing situation that proves difficult to change alone, however, such action can never be contrived or forced. One of the most intriguing phenomenon to emerge from the local and global networks established in the Pedagogy, Education and Praxis global alliance, in which the two cases presented in this article are included, has been the extent to which the networks themselves have been perceived as powerful and rewarding. As such, a more formal examination of how and why the networks have been such productive endeavours seemed warranted. Two forms of collective praxis - local and global - have been examined. The Australian case and the Nordic case both highlight local collective praxis as it emerged in the communicative spaces that were created by the local networks. With the formation of the international network, a form of global collective praxis followed.

\section{Setting the scene}

We have undertaken a retrospective analysis of the work lives of two groups of academic researchers choosing to work collectively. Specifically, we sought to identify the conditions of practice that have enabled and sustained these academics in terms of their ability to manage their daily workloads and still be productive researchers. Documents such as reflective journals, formal and informal meeting notes, email conversations and published works have been examined and analysed in the two cases. In addition, a questionnaire was sent to all participants in the two case study groups seeking voluntary responses to questions about: the existing conditions and practices within the network; the main achievements of the group from personal and professional perspectives; the relationship between the work of the group and their institution; and challenges of belonging to the group. Eight out of nine members responded to the questionnaire in the Australian group and twelve out of fifteen responded in the Nordic group. Member checking was also sought from specific colleagues who were asked to read and respond to our interpretation of events or to contribute to clarifying conversations. By presenting and analyzing these cases we have undertaken a 'cultural audit' (Gappa, et al., 2006, p. 146) to identify coherent ways of becoming and being, and sometimes surviving as, an academic. While many practice architectures pre-figure or control practice from external sources, these cases of communicative action capture enabling 'practice architectures' that were collective, reflexive and emancipatory in nature (Kemmis \& Mctaggart, 2004).. 


\section{An Australian case: The PEP group}

In 2005, an invitation to meet and discuss the notion of praxis and its relationship to our existing and future work as researchers was extended to the staff in the School of Education at Charles Sturt University by Professor Stephen Kemmis. At the time, the staff was experiencing many of the traditions and changes documented in other literature and identified earlier in this article. As a result of this open invitation, nine colleagues began to meet regularly to articulate and theorise their ideas about pedagogy, education and praxis (PEP) - a theme that Professor Kemmis had been developing with international colleagues. As such, the members referred to themselves as the PEP group. For some, the concept of praxis was a novel and challenging one whilst other members of the group had been theorizing the role of praxis and its connections to education and pedagogy for many years. The nine colleagues were at varying stages in their academic career ranging from a full time doctoral student, to early career and experienced researchers and a full research professor. The initial, informal meetings gradually became more focused on the publication of a book (Kemmis \& Smith, 2008) that documented publicly the ideas and developing understandings of praxis and how it is enabled and constrained in a variety of education settings.

\section{Carving time and space: The blue lounge process}

Carving out the time and space to engage in 'work worth doing' was identified in some form by all members as having a major impact on the success of the group. In the beginning, meetings lasting between one and two hours were often held at the university coffee shop so participants could get away from phones and other distractions. The blue lounge process represents an emerging 'practice architecture' - the creation of a time and space outside the university setting that was established during our subsequent meetings as they evolved into full day sessions. In this instance, the new space for our meetings was a home where four blue lounges accommodated the whole group very comfortably and thus, the name of the process was conceived. This type of practice architecture was relational in nature and is therefore distinguished from other practice architectures such as policies or performance management processes because it was not imposed externally. Rather, the blue lounge process parallels the concept of 'relational architectures' developed by Edwards-Groves, Brennan-Kemmis, Hardy and Ponte (this issue) in that the process was evolving and self-determining with a focus on what might be rather than what is.

According to most group members the blue lounge process was seen as conducive to productivity and vital in terms of 'shielding' them from outside distractions. Other aspects that were perceived to be rewarding included: the 'freedom to think and talk creatively'; a certain 'appeal to the intellect'; and being proactive about 'creating the conditions for being together and not just talking about it or blaming the institution'. Group members recognised that the blue lounge process was a space to 'describe, interpret and critically reflect together' and to develop mutual understandings that 'moved their thinking forward'. Still, personal and professional challenges accompanied this type of collaboration. 'Being away from family when travelling overseas', the need to 'prioritise time when there were clashes with family commitments' and 'work-related 
deadlines' were identified as common issues that problematised this process. In addition, one member commented that 'being challenged philosophically' was difficult at times, however, the same member wrote that it also 'provided the stimulus for reinvention'.

The tenor of the initial meetings and the subsequent 'blue lounge process' provided an environment that was so stimulating and personally rewarding it enlivened its members to an extent that they all became increasingly committed to ensuring that 'carving out' time and space to continue meeting would remain a priority. The use of the metaphor of 'carving' by more than one member is significant. At times it became necessary to deliberately whittle away or etch out a time and space that would allow the group to work together in ways that suspend some of the day-to-day demands and exigencies of work in the modern university. In essence, what existed within the group were the conditions for communicative action where it was possible for a group of academics to 'reach in' to get a critical grasp on problems and issues and to make mature and experienced choices about how things might be transformed (Kemmis \& Mctaggart, 2004). Somewhat ironically, the PEP group was able to meet the challenges of the workplace by stepping out of it to do the kinds of thinking, writing and research they most valued. In Wenger's (1998) terms, joint enterprises such as the writing of the book were mutually negotiated and accountability for action was shared amongst the members. As a result, this type of communicative space supported a sense of solidarity and and.political efficacy that was not felt before the group was formed. While the existence of the group clearly had its challenges, this kind of critical community established a 'safe haven' that allowed for inclusive conversations, mutual understanding and unforced consensus about 'work worth doing'. As one member commented, the blue lounge process provided 'food for our souls'.

\section{Enabling academic identity and academic freedom}

Academics are first and foremost human beings. It is not surprising that so many of the responses to the questionnaire could be connected to the concept of identity. An emphasis on academic identity highlights the humanistic nature of our social, cultural and historical actions and interactions. An essential aspect of academic identity is the extent to which an academic develops a sense of belonging where he or she experiences mutual engagement in worthwhile practices, alignment of personal and institutional goals and the ability to imagine oneself as being connected to broader ideas and possibilities (Wenger, 1998). The opportunity to nurture and sustain academic freedom was a compelling feature for the members of the Australian group. The type of freedom for intellectual expression and inquiry that the PEP group experienced led to group members feeling confident enough to define and design the structure and focus of their research agendas based on a developing sense of autonomy and control. Comments such as 'the ability to generate our own agenda for research', 'being the architect of my life' and developing a sense of 'anarchic freedom' were all attributed to the existence of the PEP group. Another member made mention of the 'ensuing confidence in other aspects of my work' that developed as a result of her participation in the blue lounge process. These responses all highlight the importance of nurturing an academic's freedom to make the type of decisions that matter most to the academics themselves - the type of decisions that 
resonate with his or her moral commitments and ideals about education and what it means to balance being an educator and a researcher. There was also clear recognition and agreement that the style of leadership within the group supported these conditions and was a contributing factor in its success.

\section{Disguised leadership}

For the Australian group, the personal and intellectual generosity of the instigator of the PEP group allowed for professional growth, initiative and the type of leadership perceived by one member as 'disguised' in that it was often 'hidden' amongst the members. Another member suggested that 'the group is almost entirely composed of leaders, which means that things happen and keep happening by themselves'. Some of the ways in which leadership was 'disguised' within the group included the actions of particular members who: took the initiative to maintain good record keeping and disseminate meeting notes; produced the first draft of a co-authored article or chapter so that it could be critiqued and developed further; sought global alliances with other institutions to add new perspectives to current research; instigated a new project proposal that would continue to connect group members in a joint enterprise; and took responsibility to bring closure to a joint project when others were pressed for time.

The potential for increased productivity as a result of this disguised leadership was another feature highlighted as an enabling aspect of the PEP group. While the level of productivity was welcome, one member pointed out that 'one of the critical features of the leadership was not rushing towards pre-determined goals or the production of technical products (a book) by ensuring time was taken to dwell and ruminate on ideas'. What is important to note is the duality of purpose underlying the group's productive activity. From its inception, the PEP group maintained a strategic alignment between its negotiated goals and the strategic plan of the university in which the members worked. The high level of productivity was attributed to the negotiation of 'clear work plans for long and short term goals'. The fact that 'the work in the group dovetails neatly into...broader research and teaching responsibilities within the university' meant that the opportunity for professional growth that the PEP group provided complemented the university's institutional goals. Such political agency can initially be attributed to the instigator of the group who had a vision of 'strengthening collaborative research in the School of Education around themes of practice' and 'rather than individual projects, my aim was to involve colleagues in collective work that would make a significant and distinctive contribution to the University's research strategy and aspiration to be a university of the professions'.

This kind of strategic intention and observance cannot be underestimated in the current climate of higher education settings. The work of the PEP group may not have been deemed so successful by the university if it had not complemented institutional goals, even if the wellbeing and personal growth of its members was flourishing. The collaborative and 'disguised' leadership combined with the rewarding and 'tangible' outcomes all contributed to a 'sense of pride in our achievements'. In turn, these practices 
ensured the group's legitimacy and collective power which has subsequently led to institutional recognition through additional funding for future projects.

\section{A Nordic Case: The Action Research Network}

Initially, Professor Tom Tiller brought together a group of colleagues and doctoral students from the University of Tromsö (Norway) with a mutual interest in, and experiences with, action research and action learning. The joint enterprises of writing a book and presenting at research conferences extended the work of the group to include researchers from other countries. Colleagues with a professional interest in action research were invited to join, either as writers in books or commentators on symposia arranged for conferences. Successively, a Nordic network of like-minded professionals was formed. It has developed into a dynamic working group with members from four Nordic countries (Norway, Sweden, Finland and Iceland) who share similar professional backgrounds and experiences from different kinds of educational settings (pre-school to university) and meet on a regular basis (2-3 times a year). Over time, the group has selforganized its internal work by having a coordinator in each of the countries (Iceland excluded) and an informally appointed leader, each of whom had been actively forming contacts with academics outside the network. The coordinators have been instrumental in continuing to develop and sustain the Nordic connection. The ongoing internal dynamics of the group can be attributed to the fact that the members are at different stages of their academic careers ranging from senior researchers to doctoral students. The professional interest of the group is related to the role of action research in school development (e.g. professional development, school leadership) and the ways in which action research connects theory and practice. The fact that action research is a relatively new form of research in academia, and as a consequence, suffered from a lack of history and regard also contributed to the purpose and the mission of the network. While Nordic countries share the same kind of welfare state ideology, there are still enough differences between the educational systems to create constructive tension and dynamics that have kept the work of the group alive.

\section{An organic, self-renewing structure characterized by inclusiveness}

According to the questionnaire responses, the work within the group has been characterized by openness, inclusiveness, solidarity and tolerance. The inclusiveness of the group was highlighted by many members as an enabling factor that has sustained them. One member commented that 'besides the distinct and highly respected leadership, we seem to have found quite naturally and informally a way to define and divide different and complementary roles within the network'. The informal and natural formation of writing groups and the division of responsibilities (leadership, coordinators) has always been negotiated openly. One aspect of this is the informal, distributed supervision of the doctoral students taking place within the group, a kind community of 'supervisory practice' described by Wisker, Robinson and Scacham (2007). This 'peer-supervision' has been enabled by the fact that the network has brought together doctoral students from a number of universities. Of particular significance was the international doctoral seminar held during a research symposium in Australia in February 2008. Even though this event 
was seen as 'remarkable', it was also one of the most challenging times for some members because of the need to present their work in English.

While the relatively informal nature of the dynamics in the Nordic network has been perceived as positive, a concomitant strength is that the work of the group has always been carefully planned in advance. The process of joint and committed planning, during which 'different options and alternatives are brought forward, discussed and reflected upon' has been important for the network. The regularity and commitment to this planning is also highly dependent on both 'democratic and distinct leadership that is based on mutual respect and reliance'. A crucial factor that has impacted on the success of the network has been negotiating plans for the group that are 'mostly a three-year plan'. Within these plans, strategic opportunities for meeting regularly are factored in. The group always arranges to meet the day before a particular conference that brings many of the members together. Having recognized the success of the work within the network that has provided credibility and legitimacy, some members also pointed out that 'we have never been just one happy family'. With different backgrounds and educational cultures there have been many times when members have not been able to 'immediately understand each other or find a common ground from which to work'. However, such diversity has also led to a developing sense of acceptance, respect and patience for different views, voices and opinions.

\section{An evolving network: Widening circles}

Within the responses from the Nordic network, there was common agreement that the group was constantly evolving and widening its circles of influence and connection. The structuring of the internal work has been dynamic. Members have worked together in varying group formations based on a specific interest at a certain time. New members, commentators and discussants have been continually invited to join the group or contribute to group meetings. At the same time, some of the existing members had to temporarily leave the active network for different kinds of professional reasons (new appointments, intensive periods of work) but have been welcomed back if or when they return. This element of openness has also allowed for 'visiting members' to join the network for shorter periods of time to contribute to writing a paper or book or copresenting at a conference.

Another important and recurring element of the work in the Nordic network has been openness towards the field of professional educational practice. The exchange of ideas and experiences and 'the knowledge creation' within the group is directly connected to, and usable within, the professional work (e.g. development projects) that members are involved in outside the network. The majority of the members in the group were once teachers or principals in schools and choose to be continuously involved in development projects/continuing education programs in schools. There is a natural connection of interests and expertise outside academia. This has been evidenced in the nature of the books (see, for example, Rönnerman, Moksnes-Furu \& Salo, 2008) and articles published by the group and the number of researcher-practitioner conferences organized by the network. 
One of the key tenets in the Nordic network has been the philosophy of 'thinking big and acting small'. The coordinators of the network have been very careful not to take 'too big a step too quickly.' The goals have been kept manageable and achievable. According to one member, 'the backbone of the network' is the ongoing, regular academic work that focuses on 'the concrete goals and aims of producing articles and presenting papers' which has yielded 'noticeable results that give us both credibility and legitimacy within our respective academic institutions'. As a consequence, the decision to participate in an international collaboration focused on Pedagogy, Education and Praxis in 2006 was not an easy one. The circle of influence was widening. In contrast to the Australian group, the invitation to become part of a wider international network or global alliance was presented to the Nordic network at a point in time when they had worked together for a number of years and had already developed a distinct group identity and sense of belonging. The determining factor for the group agreeing to commit to the international alliance was the perception that writing a book in the proposed series would mirror the model of working together already established by the Nordic network. Having met members of the Australian group at previous conferences, some members of the network held a collective sense that 'we had found yet another group of likeminded professionals with not only the same kind of research interests but also the same kind of values and beliefs'.

\section{Collective praxis: an opening of communicative space}

The two cases represent intellectual engagement characterized by different forms of connectedness. We argue that the nature and type of practices evident in these cases led to a shift from personal to collective intellectual space which makes them cases of collective praxis. Personal praxis and collective praxis are interrelated, but are able to be analysed separately according to their purpose and actions. Clearly, the quotes have demonstrated that the development of personal praxis continued to be shaped, questioned and affirmed for individual members. But what constitutes collective praxis as a viable and valued-added model of intellectual engagement? Collective praxis is a capacity building model of intellectual engagement that builds communication and partnership. Its impetus comes from the desire of like-minded professionals to overcome dissatisfactions and address issues that threaten personal praxis. What are the core features of collective praxis that can increase the capacity of academics to nurture and manage change? What have the university-based and global alliances provided that was not evident before they were established? We characterize these core features as two different forms of connectedness - collegiality and intentionality - that represent different but complementary purposes.

\section{A culture of collegiality}

Collegiality has many dimensions that can enrich the work life of academics, and result in job satisfaction (Ambrose, Huston and Norman, 2005). The basic human valuing of people is the core of any relationship (Gappa, et al., 2006). The nature of the relationships that nurture collective praxis are exemplified by comments from both cases: having a 
framework to be in gave me a sense of belonging; a sense of meaningfulness and togetherness that fostered trust and solidarity; the group allowed me to believe in the good of what I was doing; and I developed an openness to new ideas. The extended audiences within and outside personal working spaces provided alternate perspectives or lenses 'to magnify and clarify thinking'. There was a 'genuine willingness to critique and interrogate each other's ideas predicated on respect for each other and our collective work'. Such collaborative links enabled cross-disciplinary work and access to different bodies of research that would otherwise have been unavailable. Making sense of a particular situation or trying to do the right thing can sometimes require conflict and confrontation. Many participants noted that a positive aspect of widening their circle of interaction was the training in argumentation they experienced while defending their position in a group of professional friends. Listening to, and participating in, various kinds of structured and spontaneous conversations during which arguments, views and experiences were scrutinized led to a deeper consciousness for participants in both studies. The internally diverse and differentiated membership allowed for revelation, anticipation and building connections that ensured healthy and open dialogue and provided a 'disciplining function' that guarded against self-regulation (Kemmis \& McTaggart, 2004).. The way in which both of the groups have constituted themselves can also be understood in terms of the Nordic tradition of a study circle, based on recognition of diverse identities, horizontal relations, equal participation, deliberations and democratic decision-making (Larsson, 2001)

New ways of interacting due to the availability of new technologies increased a sense of connectedness in the PEP network that is unbounded by time and distance. Time zones were somewhat invisible for all the participants in the global alliance and allowed for the establishment of new dialogue partners that might be in the room next door or across the globe. With the onset of email correspondence, a message could be sent at any time of the day or night and lie in wait for its recipient. The turnaround times for mentoring of writing and editing articles are no longer prohibitive and make the possibilities seem endless. However, one of the challenges is that some participants found it more difficult to separate their personal and professional lives because of the increased flexibility and access that these same technologies have offered.

One of the most rewarding connections between the two networks emerged from the 'language wash' process that occurred during the writing of the books in the Pedagogy, Education and Praxis series. From the Nordic perspective, writing for an English speaking audience brought its own demands and personal challenges that were supported by the Australians' commitment to assisting their colleagues to transform 'Swenglish' or 'Finglish' into English. This process provided an unexpected opportunity for both groups to engage in stimulating reflections upon theoretical understandings, similarities and differences between cultural interpretations of particular educational concepts (e.g. pedagogy, praxis, Bildung, study circle) as well as critical reflection required when justifying a personal stance. While the development of collective praxis in these cases demanded the acceptance of diversity, uncertainty and complexity as key aspects of being and becoming an academic it also created a 'safe haven' for developing such acceptance in non-threatening and supportive ways. 
Even though it was commonly recognised that communicating electronically with our international partners was an effective way of sustaining our collective praxis, a significant marker that influenced its success was the opportunity to meet face to face, enabling colleagues to became friends rather than 'disembodied persons at the end of an email trail'. In fact, the social aspect of the networks was highly valued by every respondent. The social gatherings and interactions, 'to which everybody seems to be highly committed', the singing, and the good humour of the people in the networks have all contributed to a culture of collegiality. Paradoxically, these aspects that are so deeply appreciated and conducive to satisfying work cannot be planned for or designed - they either develop or they do not. As a consequence, it is not surprising that scholarly papers rarely make mention of such findings. However, as other scholars have found, the emotional landscape of education is an equally important terrain that warrants our direct attention (Hargreaves, 2000).

\section{Intentionality of purpose}

Collective praxis in academic life is equally dependent on the personal praxis of an individual academic and the practice architectures - the organizational structures, policies and practices within the institution in which they work. As such, strategic alignment between these factors allows academics to maintain a duality of purpose that is both personally and professionally rewarding. Within both cases, there were a number of deliberate actions that explicitly and intentionally addressed the tensions between accountability and agency. In the Australian group, intentionality was evident in the ways in which the members strategically aligned their goals and interests with those of the university so that they could continue doing the kinds of work they considered most rewarding. For the Nordic network, the intentionality related more to gaining legitimacy for their work outside their own institutions. It aimed to increase the profile and agency of action research by forming a collective of like-minded professionals in other parts of the world that were successfully engaging in the process of action research. According to a number of responses to the questionnaire, the widening of the circle to include membership in an international network has helped both groups gain valuable legitimacy and recognition 'at home' in their own universities. Not only did both groups engage in 'work worth doing', they very purposefully documented evidence of the outcomes in terms of productivity that contributed to 'the force of better argument' that influenced exisiting structures and procedures (Kemmis \& McTaggart, 2004). Another aspect of intentionality seen in both cases was the way in which research was seen as an opportunity for professional learning, mentoring and growth. In a climate where time and space seem difficult to negotiate, innovative ways of integrating professional growth opportunities into ongoing work seems like a strategic imperative for academics and institutions alike .

In summary, there was an overwhelming response by members of both groups that clearly places a human face over the existing exigencies that threaten to dominate academic institutions. In workplaces that are becoming analogous with a commodity in a marketplace, there is a high risk that a sense of humanity - of the people most affected by 
workplace conditions - may become diminished, lost in the neoliberal discourses of managerialism, functionality and accountability and victim to the suffocating effects of fiscal constraints (Gappa, et al., 2006; Gould, 2006). In contrast, the local and global communities that have emerged from the Pedagogy, Education and Praxis network have supported the development of collective praxis - a way of being that allows for academic intimacy - the kind of shared understanding that produces a tangible sense of solidarity and fosters human connectedness and confidence. By developing collective praxis as a model of intellectual and collaborative engagement and action, academics can interpret and transform the existing procedures and structures in which they work. As nodes in an international network, the two cases of collective praxis have illustrated how a culture of collegiality and intentionality of purpose within and across university contexts and disciplines can be enabled and safeguarded in order to sustain and enliven academic work. Such history-making action simultaneously supports the beliefs and values of academics as they contribute to the visions and goals of the institutions in which they work.

\section{References}

Altbach, P.G. (2001). Academic freedom: International realities and challenges. Higher Education, 41 (2) , 205-219.

Ambrose, S., Huston, T., \& Norman, M. (2005). A Qualitative method for assessing faculty satisfaction. Research in Higher Education, 46 (7), 803-830.

Gappa, J. M., Austin, A., \& Trice, A. G. (2007). Rethinking faculty work: Higher education's strategic imperative. San Francisco, CA: Jossey-Bass.

Gould, E. (2006). Professor or Knowledge Worker? The Politics of Defining Faculty Work. Higher Education in Europe, 31 (3), 241-249.

Habermas, J. (1996) Between Facts and Norms (trans.William Rehg). Cambridge, Massachusetts: MIT Press.

Hargreaves, A. (2000). Mixed emotions: Teachers' perceptions of their interactions with students. Teaching and Teacher Education, 16(8), 811-826.

Karran, T. (2007). Academic Freedom in Europe: A Preliminary Comparative Analysis. Higher Education Policy, 20 (3), 289-313.

Jones, G. A. (2006). The restructuring of academic work: Themes and observations. Higher Education in Europe, 31(3), 317- 325.

Kemmis, S., \& Grootenboer, P. (2008). Situating praxis in practice: Practice architectures and the cultural, social and material conditions for practice. In S. Kemmis \& T. J. Smith (Eds.), Enabling Praxis: Challenges for Education (pp.37-62). Rotterdam: Sense.

Kemmis, S., \& McTaggart, R. (2004). Participatory Action Research: Communicative action and public spheres. In N. Denzin and Y. Lincoln (Eds.). The Handbook of Qualitative Research, $3^{\text {rd }}$ edition, Beverly Hills, CA: Sage Publications.

Kemmis, S., \& Smith, T. J. (Eds.). (2008). Enabling Praxis: Challenges for Education. Rotterdam: Sense.

Lafferty, G. \& Fleming, J. (2000). The Restructuring of Academic Work in Australia: Power, management and gender. British Journal of Sociology of Education, 21 (2) 257267. 
Larsson, S. (2001). Seven aspects of democracy as related to study circles. International Journal of Lifelong Education, 20 (3), 199-217.

Rönnerman, K., Moksnes Furu, E., \& Salo, P. (Eds.). (2008). Nurturing praxis: Action research in partnerships between school and university in a Nordic light. Rotterdam: Sense.

Wenger, E. (1998). Communities of practice: Learning, meaning and identity. New York, NY: Cambridge University Press.

Wisker, G. Robinson, G. \& Scachan, M. (2007). Postgraduate research success: communities of practice involving cohorts, guardian supervisors and online communities. Innovations in Education and Teaching International, 44 (3), 301-320. 